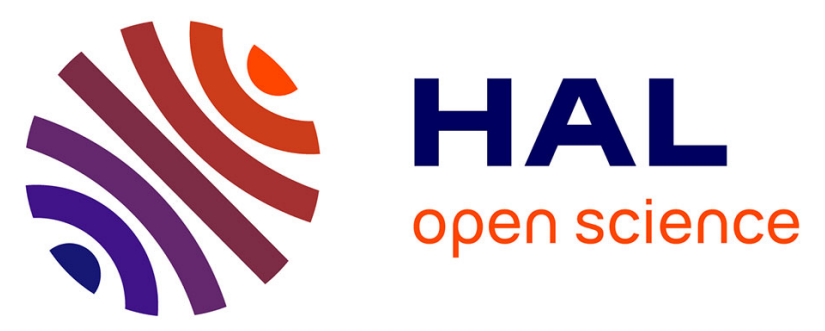

\title{
Study of the Influence of the Fabrication Process Imperfections on the Performances of a Claw Pole Synchronous Machine Using a Stochastic Approach
}

Sijun Liu, Hung Mac, Stéphane Clenet, Thierry Coorevits, Jean-Claude Mipo

\section{- To cite this version:}

Sijun Liu, Hung Mac, Stéphane Clenet, Thierry Coorevits, Jean-Claude Mipo. Study of the Influence of the Fabrication Process Imperfections on the Performances of a Claw Pole Synchronous Machine Using a Stochastic Approach. IEEE Transactions on Magnetics, 2015, 52 (3), pp.1-4. 10.1109/TMAG.2015.2477848 . hal-01273246

\section{HAL Id: hal-01273246 \\ https://hal.science/hal-01273246}

Submitted on 12 Feb 2016

HAL is a multi-disciplinary open access archive for the deposit and dissemination of scientific research documents, whether they are published or not. The documents may come from teaching and research institutions in France or abroad, or from public or private research centers.
L'archive ouverte pluridisciplinaire HAL, est destinée au dépôt et à la diffusion de documents scientifiques de niveau recherche, publiés ou non, émanant des établissements d'enseignement et de recherche français ou étrangers, des laboratoires publics ou privés. 


\title{
Study of the Influence of the Fabrication Process Imperfections on the Performances of a Claw Pole Synchronous Machine Using a Stochastic Approach
}

\author{
S. Liu ${ }^{1,2}$, H. D. Mac ${ }^{3}$, S. Clénet ${ }^{1}$, T. Coorevits ${ }^{4}$ and J. C. Mipo ${ }^{2}$ \\ ${ }^{1}$ L2EP, Arts et Métiers ParisTech, 59046 Lille cedex, France \\ ${ }^{2}$ Valeo Engine and Electrical Systems, 94017 Créteil Cedex, France \\ ${ }^{3}$ L2EP, University Lille 1, 59655 Villeneuve d'Ascq cedex, France \\ ${ }^{4}$ MSMP, Arts et Métiers ParisTech, 59046 Lille cedex, France
}

\begin{abstract}
In mass production, fabrication processes of electrical machines are not perfectly repeatable with time, leading to dispersions on the dimensions which are not equal to their nominal values. The issue is then to link the dispersions on the dimensions which are uncertain to the performances of electrical machines in order to evaluate their influence. To deal with uncertainty, there is a growing interest in the stochastic approach, which consists in modelling the uncertain parameters with random variables. In fact, this approach enables to quantify the influence of the variability of the uncertain parameters on the variability of the quantities of interest. In this paper, a stochastic approach coupled with a 3D Finite Element model is used to study the influence of the fabrication process imperfections like the rotor eccentricity and the stator deformation on the performances of a claw pole synchronous machine.
\end{abstract}

Index Terms-Claw Pole Machine, Finite Element Method, Eccentricity, Stator Deformation, Uncertainty Quantification, Stochastic Model

\section{INTRODUCTION}

$\mathrm{D}$ UE to the imperfections of the fabrication process, deviations occur on the manufactured part dimensions of an electrical machine, which are not equal to their nominal values. For example, the inner surface of the stator doesn't fit a perfect cylinder shape or the rotor is not perfectly centered (eccentricity) [1-8]. These deviations introduce parasitic effects on the behavior of the electrical machine. Nowadays, if the deviations are perfectly known and constant, numerical models are available to evaluate their effects and particularly one can check if the electrical machine still satisfies the specification (if it is the case, these deviations can be accepted). In [8] for example, a 3D Finite Element model has been used to study the influence of the stator deformation on the performance of a claw pole synchronous machine. In practice, these deviations versus the nominal dimensions are not perfectly known especially in mass production where the fabrication process changes with time. It introduces variability on the dimension deviations. The behavior of the machine is then not the same from a machine to another. Consequently, one has to quantify the effect of this variability on the electrical machine behavior and check if the specifications are still satisfied. If not, the most influential dimensions on the behavior should be identified in order to act on the fabrication process to reduce their variability. The stochastic approach enables to evaluate the impact of the dimension dispersion the performances of the electrical machine and also provide tools for a global sensitivity analysis [9]. The issue is then to be able to model the variability of the dimensions with random variables. Until now, the stochastic approach is generally applied with random parameters modelled from expertise and almost no measurement to characterize the dispersion [11].

In this paper, we propose to quantify, using a stochastic approach, the influence on a claw pole machine performances of the dimension dispersions introduced by a process of fabrication. The dispersions on the dimensions are modelled using a probabilistic model extracted from measurements on 40 machines [9]. It appears that the most significant imperfections are the eccentricity of rotor and the deformation of the stator inner surface which cannot be considered as a perfect cylinder. A 3D non linear finite element model of the machine with a parameterized geometry has been developed to account for any eccentricity and complex inner surface shape of the stator. To propagate the uncertainty, a stochastic non intrusive approach based on sparse polynomial chaos expansion has been applied. Then, statistics has been extracted in order quantify the influence of the imperfections on the performances of the electrical machine.

\section{CHARACTERIZATION AND MODELLING OF THE IMPERFECTIONS OF THE CLAW POLE MACHINES}

A measurement campaign has been made on parts of 40 electrical machines. Each machine has been disassembled into three parts (the stator, a bracket and the rotor). Each part has been measured using a coordinate measuring machine (Fig.1). To characterize the eccentricity, the three parts have been virtually reassembled [10]. As expected, the measured dimensions were not equal to the nominal dimensions. The inner surface of the stator reconstructed from 576 measured points corresponding to the radii of the 36 slots measured on 16 layers regularly distributed along the depth. In Fig.2, we can see clearly that the reconstructed surface is not a perfect 
cylinder. Moreover, the imperfections of the 40 machines were not identical and it appears a dispersion due to the nonrepeatability of the process of fabrication. The analysis of the measurement showed that the major imperfections were the eccentricity of the rotor (static and dynamic) and also the deformation of the inner surface of the stator. We should mention that this conclusion can be drawn only for the considered fabrication process and cannot be generalized to any other fabrication process of claw pole machines.

\section{A. Caracterisation of the eccentricity}

To characterize the eccentricity, three axes should be determined: the rotation axis of the rotor, the axis of the rotor and the axis of the stator. By calculating from the measured dimensions, the intersections of these axes with two plans P1 and $\mathrm{P} 2$ defined by the two bearings of the rotor shaft. The rotation axis of the rotor is the reference and defined the center of the coordinate system in each plan. The intersections of the rotor and stator axes with the planes $\mathrm{P}_{1}$ and $\mathrm{P}_{2}$ are denoted $\mathrm{M}_{\mathrm{r} 1}, \mathrm{M}_{\mathrm{s} 1}, \mathrm{M}_{\mathrm{r} 2}$ and $\mathrm{M}_{\mathrm{s} 2}$ axes. It appears that the points $\mathrm{M}_{\mathrm{r} 2}$ and $\mathrm{M}_{\mathrm{s} 2}$ are not dispersed and can be considered coincident with the origin $(0,0)$ as shown in Fig. 2. However, the dispersions of $\mathrm{M}_{\mathrm{r} 1}$ and $\mathrm{M}_{\mathrm{s} 1}$ can not be neglected and are not coincident which leads to an eccentricity. The mounting of the two shaft bearings is not the same and is much more tightened on the side of the plane $\mathrm{P}_{2}$ leading to less dispersion. In order to emphasize the three states of eccentricity (static, dynamic and mixed), we introduce a new parametrization of the intersections points $M_{r 1}$ and $M_{s 1}$ in the plane $P_{1}$. Four new parameters $(\alpha, s r, \beta s, \beta r)$ presented in Fig. 3 are introduced.
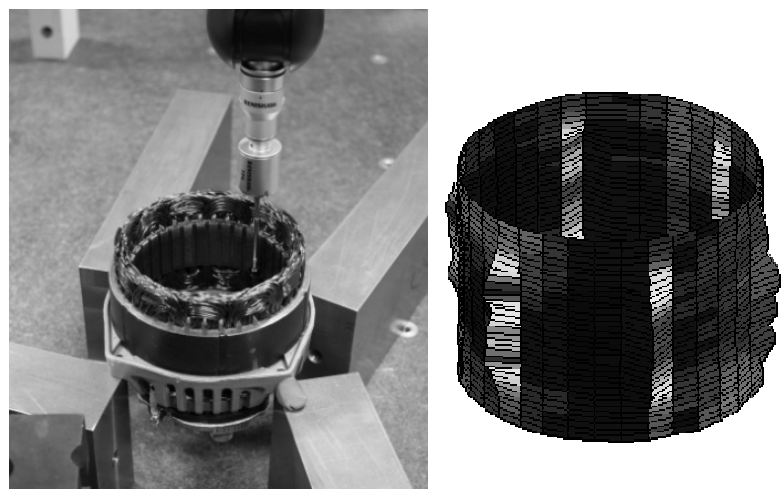

Fig. 1. Measurement of the inner surface of the stator (left) and 3D representation of the deformation of this surface from the measured points (right).

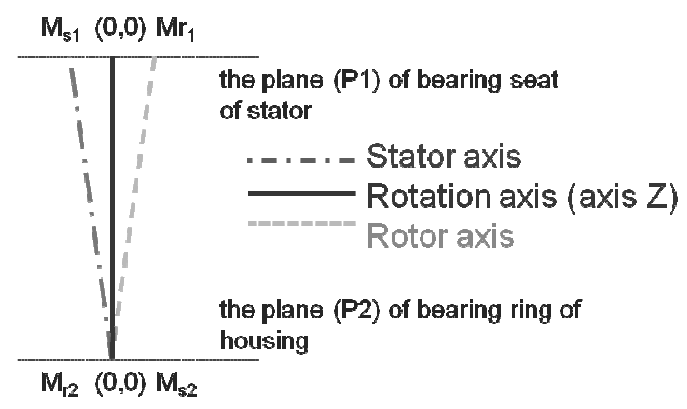

Fig. 2. Definition of the three axes and the points $M_{r 1}, M_{r 1}, M_{r 2}$ and $M_{s 2}$.
The parameters $(\alpha, s r)$ define the distance between the different axis at $\mathrm{t}=0$. The two other parameters $(\beta \mathrm{s}, \beta \mathrm{r})$ represent the angles between the stator axis and the rotor axis with the axis of the phase $\mathrm{A}$ of the stator also at $\mathrm{t}=0$. With the proposed model, only one parameter characterizes the type of eccentricity and we have: $\alpha=1$ static eccentricity, $\alpha=0$ dynamic eccentricity, $0<\alpha<1$ mixed eccentricity. For each of the 40 machines, the previous parameters have been identified leading to a sample of 40 realizations for each parameter $\alpha, \mathrm{sr}, \beta \mathrm{s}, \beta \mathrm{r}$. Statistical tests showed that $\alpha$ can be modeled by a gaussian Random Variable (RV), sr by a lognormal RV, which statistics are reported in Table 1 , whereas $\beta$ s and $\beta \mathrm{r}$ by uniform RVs on the interval $\left[0,360^{\circ}\right]$.

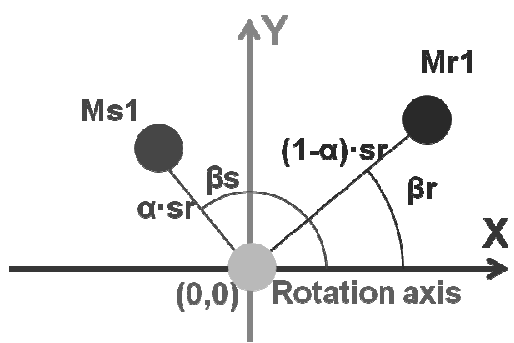

Fig. 3. Definition of the parameters $(\alpha, \mathrm{sr}, \beta \mathrm{s}, \beta \mathrm{r})$ modelling the eccentricity

\section{B. Caracterisation of the stator inner surface}

An analysis of the measurement of the 40 machines showed that the deformation of the stator inner surface can be accurately be modelled by considering the radius $r(i, z)$ of the $\mathrm{i}^{\text {th }}$ tooth at the depth $\mathrm{z}(0 \leq \mathrm{z} \leq 1$ with 1 the length of the stator $)$ $[5,6]$ :

$$
\begin{aligned}
& r(i, z)=h_{0}+h_{2 \sin } \sin \left(\frac{i \pi}{9}\right)+h_{2 \cos } \cos \left(\frac{i \pi}{9}\right) \\
& +h_{3 \sin } \sin \left(\frac{i \pi}{9}\right)+h_{3 \cos } \cos \left(\frac{i \pi}{6}\right) \\
& +\frac{4 h_{6 \sin }}{1^{2}} z(z-1)\left[\begin{array}{l}
\left.\sin \left(\frac{i \pi}{9}\right)+k_{6 c} \cos \left(\frac{i \pi}{9}\right)+k_{12 s} \sin \left(\frac{2 i \pi}{3}\right)\right] \\
+k_{12 c} \cos \left(\frac{2 i \pi}{3}\right)+k_{18} \cos (i \pi)
\end{array}\right]
\end{aligned}
$$

The parameters $\mathrm{k}_{6 \mathrm{c}}, \mathrm{k}_{12 \mathrm{~s}}, \mathrm{k}_{12 \mathrm{c}}$ and $\mathrm{k}_{18}$ are fixed parameters. The 6 parameters $\mathrm{h}_{0}, \mathrm{~h}_{2 \sin }, \mathrm{h}_{2 \cos }, \mathrm{h}_{3 \sin }, \mathrm{h}_{3 \cos }$ and $\mathrm{h}_{6 \sin }$ depend on the machines. Statistical tests showed that the variability of the last 6 parameters could be modelled by gaussian RV which means and standard deviations are reported in Table I. It should be noted that the origin of the deformation associated to the previous parameters can be linked to a stage of the fabrication process. For example, the terms $h_{2 \sin }$ and $h_{2 \cos }$ are related to the assembling of the lamination stack and the housing with 4 screws. The term $\mathrm{h}_{6 \text { sin }}$ is related to the six welding bands on the side of lamination stack leading to the retraction of six teeth over the 36 stator teeth.

$$
\text { TABLE I }
$$

\begin{tabular}{|c|c|c|c|c|c|c|c|c|}
\hline & $\overline{\mathrm{h}_{0}}$ & $\mathrm{~h}_{\mathrm{sin} 2}$ & $\mathrm{~h}_{\mathrm{cos} 2}$ & $\mathrm{~h}_{\mathrm{sin} 3}$ & $\mathrm{~h}_{\cos 3}$ & $\mathrm{~h}_{\sin 6}$ & sr & $\alpha$ \\
\hline MEAN $(\%)$ & 2.49 & 1.2 & 3.6 & 0.49 & -0.8 & 29,5 & 31.6 & 0.469 \\
\hline $\operatorname{STD}(\%)$ & 2.4 & 3.9 & 3.5 & 1.4 & 1.4 & 9,1 & 13.6 & 0.19 \\
\hline
\end{tabular}

MEAN AND STANDARD DEVIATION (STD) OF THE PARAMETERS IN A DIMENSIONLESS FORM (THE AIRGAP LENGTH IS THE REFERENCE) 
Once the uncertainties on the inputs have been modelled, we can quantify the influence of the eccentricity and of the stator deformation on the quantities of interest by propagating the uncertainties through the FE model of the electrical machine, which should be able to account all the imperfections listed above [9].

\section{FINITE ELEMENT MODEL ACCOUNTING FOR THE IMPERFECTIONS}

The eddy current effect in the stator and in the rotor has been neglected. Under this assumption, the claw pole synchronous machine has been modeled using a non linear magnetostatic model accounting for the movement. The scalar potential formulation coupled with 3D Finite Element method has been used to solve the non linear magnetostatic problem. The number of nodes and tetrahedral elements of the mesh are respectively equal to 152865 and 832514 . To account for the modification of the geometry (eccentricity and stator deformation), a method based on node displacement has been chosen instead of a remeshing method. A transformation method has been implemented in order to move adequately the nodes in order to take into account the deformation of the stator and the eccentricity. This transformation is parameterized by the uncertain parameters $(\alpha, s r, \beta s, \beta r)$ and $\left(h_{0}\right.$, $\left.\mathrm{h}_{2 \sin }, \mathrm{h}_{2 \cos }, \mathrm{h}_{3 \sin }, \mathrm{h}_{3 \cos }, \mathrm{h}_{6 \sin }\right)$. The position of the rotor is parameterized by $(\alpha, s r, \beta s, \beta r)$ which is very convenient to simulate any configuration of eccentricity. In the same way, the radius of each tooth is calculated according to the deformation of the stator inner surface given by the parameters $\left(\mathrm{h}_{0}, \mathrm{~h}_{2 \sin }, \mathrm{h}_{2 \cos }, \mathrm{h}_{3 \sin }, \mathrm{h}_{3 \cos }, \mathrm{h}_{6 \sin }\right)$ and the expression (1).

\section{UNCERTAINTY QUANTIFICATION METHOD AND GLOBAL SENSITIVITY ANALYSIS}

The inputs of the FE model being random variables, the outputs are also random variables. The issue is then to characterize them by calculating their statistics like the mean and the standard deviation but also to determine the input random variables which contribute the most to their variability. If we denote $\mathbf{p}(\theta)=\left[\mathrm{p}_{1}(\theta), . ., \mathrm{p}_{\mathrm{K}}(\theta)\right]$ the vector of the input random variables, $\mathrm{G}$, an output of the model, is a random variable $G[p(\theta)]$. To characterize it, we seek for an approximation under the form:

$$
\mathrm{G}[\mathbf{p}(\theta)] \approx \sum_{\mathrm{i}=1}^{\mathrm{P}} \mathrm{g}_{\mathrm{i}} \Psi_{\mathrm{i}}[\mathbf{p}(\theta)]
$$

with $g_{i}$ real coefficients and $\left(\Psi_{\mathrm{i}}[\mathbf{p}(\theta)]\right)_{1 \leq i \leq \mathrm{K}}$ multivariate polynomials (Polynomial chaos). To determine the coefficients $g_{i}$, a sample $\left(\mathbf{p}^{1}, \ldots, \mathbf{p}^{\mathrm{R}}\right)$ of size $\mathrm{R}$ of the realizations is generated in accordance with the probability density function of each input parameter $\mathrm{p}_{\mathrm{i}}$ The FE model is solved for each parameter realization $\mathbf{p}^{j}(1 \leq j \leq R)$ and a sample of size $R$ of the quantity of interest $G$ is obtained. Then, the Least Angle Regression (LAR) method is applied in order to identify coefficients $g_{i}[12]$.

\section{RESUlts}

We have studied the EMF and the torque when the rotor is supplied by a current I of $0.5 \mathrm{~A}$ and $4 \mathrm{~A}$ and the stator winding is at no load. The torque is then a cogging torque. At $\mathrm{I}=0.5 \mathrm{~A}$, the machine behavior is almost linear whereas at $4 \mathrm{~A}$ the machine is very saturated. The effect of the eccentricity and of the stator deformation has been studied separately. The quantities of interest are the harmonics of the EMF and the harmonics of the torque. The fundamental frequency corresponds to the mechanical frequency, the electrical frequency is 6 times higher because the machine has 6 pairs of poles. The ideal machine where the dimensions are equal to their nominal value has been first modelled. As expected, the harmonics of the EMF are of order 6, 18, 30 and for the torque 36 and 72.

\section{A. Impact of the eccentricity}

We have calculated the EMF and the torque for $\mathrm{R}=120$ realisations of the uncertain parameters. In Fig. 4, we have represented the R EMF's for I=0.5 A. We can see that they are superposed and the variation coefficient of the harmonic magnitude is lower than $1.5 \%$. Due to the saturation effect, at $\mathrm{I}=4$ A the coefficient of variation is almost equal to zero. On the torque it appears that the variability of the eccentricity has almost no influence on the magnitude of the harmonics 36 and 72. A parasitic harmonic of order 1 appears which magnitudes for the 120 realizations have been reported in Fig.5 as well as the magnitude of the harmonic 36 . The coefficient of variation of the magnitude of the harmonic 1 is equal to $70 \%$ and $64 \%$ for $\mathrm{I}=0.5 \mathrm{~A}$ and $\mathrm{I}=4 \mathrm{~A}$ respectively meaning that this harmonic is really dispersive. We can also notice a small variability of the magnitude of the harmonic 36 . However, the ratio between the mean of the magnitudes of the harmonic 1 and 36 is equal to $3.8 \%$ and $0.9 \%$ for $\mathrm{I}=0.5 \mathrm{~A}$ and $\mathrm{I}=4 \mathrm{~A}$. Consequently, even though the variability of the eccentricity is quite large it has a small impact on the machine behavior. It should be noticed that this conclusion can be drawn only for the eccentricity type considered in this analysis. The conclusion would not have been necessarily the same if the variability of $M_{\mathrm{s} 2}$ and $\mathrm{M}_{\mathrm{r} 2}$ would have been significant (see Fig. 2) for example.

\section{B. Impact of the stator deformation}

We have first quantified the effect of the uncertainties on the stator deformation. We have generated a sample of $R=200$ realizations of the input parameters $\left(\mathrm{h}_{0}, \mathrm{~h}_{2 \sin }, \mathrm{h}_{2 \cos }, \mathrm{h}_{3 \sin }, \mathrm{h}_{3 \cos }\right.$, $\left.\mathrm{h}_{6 \sin }\right)$. We have calculated the evolution of the torque in function of the position for each realization. In Fig. 6, the superposition of the 200 torque wave shapes are compared to the one of the ideal machine (the dimensions are equal to the nominal ones) for $\mathrm{I}=0.5 \mathrm{~A}$. We can see that the stator deformation introduced a low frequency effect. To characterize it, the harmonics of torque have been calculated for each realization. The influence of the parameters on the variability these harmonics has been studied by calculating the Sobol indices. The harmonics 36 and 72, which exist with the ideal machine, are not much influenced by the stator deformation. However, new harmonics of order 12 and 24 
appear. In Table II, we have reported the value of Sobol indices for $\mathrm{I}=0.5 \mathrm{~A}$ and $4 \mathrm{~A}$ for the harmonic 12 . It should be noted that only the term $\mathrm{h}_{\sin 6}$ is the most influential meaning that the variability (and the magnitude) of the harmonics 12 and 24 of the torque can only be reduced by acting on $\mathrm{h}_{6 \sin }$. As mentioned previously, the term $\mathrm{h}_{6 \sin }$ is closely related to the welding process. Consequently, the reduction of the harmonics 12 and 24 passes necessarily by modifying this stage of the fabrication process.

\section{CONCLUSION}

The stochastic approach presented enables to relate the imperfections and the variability of the fabrication process to the quantity of interest of an electrical machine. This approach segregates among all the dispersive input parameters, characterizing from a measurement campaign, which ones are the most influential. It has been shown that the considered manufactured machines, that the eccentricity has less impact than the stator inner surface deformation on the EMF and the torque at no load.

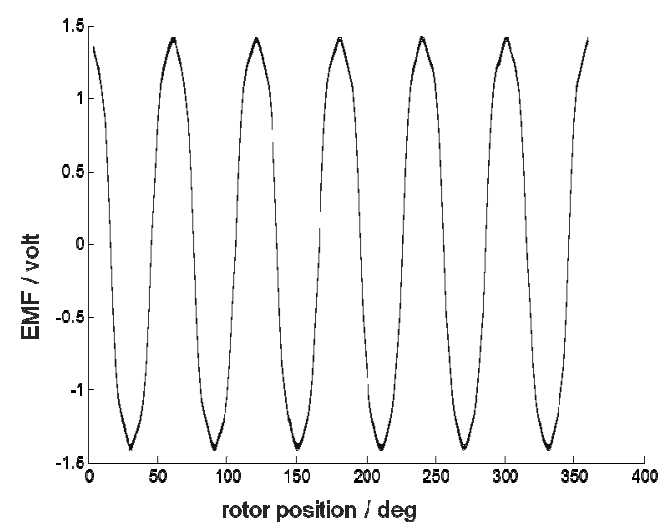

Fig.4. 120 realizations of the EMF when taking into account the eccentricity and $\mathrm{I}=0.5 \mathrm{~A}$
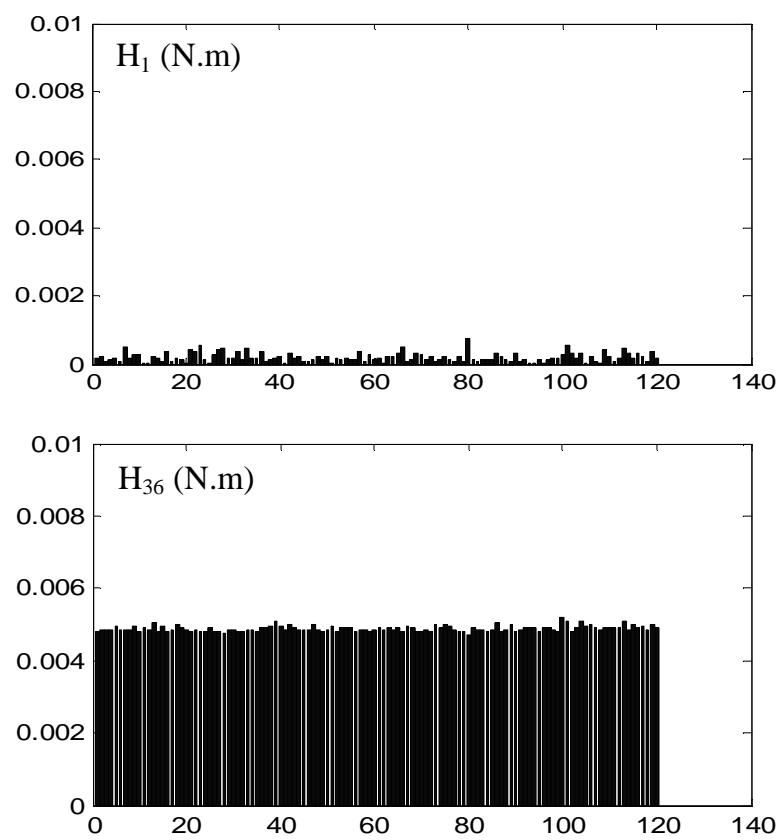

Fig.5. Magnitudes of the harmonics 1 (top) and 36 (bottom) for 120 realizations of the torque when $\mathrm{I}=0.5 \mathrm{~A}$

\section{REFERENCES}

[1] Schlensok, C. Henneberger, G, "Calculation of force excitations in induction machines with centric and eccentric positioned rotor using 2-D transient FEM", IEEE Trans. on Mag., Vol. 40(2), pp. 782-785 ,2004

[2] A. Belahcen, A. Arkkio "Computation of additional losses due to rotor eccentricity in electrical machines", Electric Power Applications, IET, Vol. 4(4), pp 259-266, 2010

[3] A. Arkkio, "Electromagnetic damping of stator vibrations in a cage induction motor", VTT SYMPOSIUM, vol. 209, pp. 25-44, 1999.

[4] B. Tanno-Iamamura, Y. Le Menach, A. Tounzi, N. Sadowski, E. Guillot, "Study of static and Dynamic eccentricities of a synchronous generator using 3D FEM", IEEE Trans. on Magn., 46(8), pp.3516-3519, 2010

[5] Z.Q Zhu, L.J Wu and M.L Mohd Jamil. "Distortion of back-EMF and torque of PM brushless machines due to eccentricity", IEEE Trans. on Magn., 49(8), pp.4927-4936, 2013

[6] M.F. Hsieh, Y.H. Yeh "Rotor eccentricity effect on cogging torque of pm generators for small wind turbines", IEEE Trans. on Mag., 49(5), pp. 1897-1900, 2013

[7] S. Nandi, H.A. Toliyat, X. Li, "Condition Monitoring and Fault Diagnosis of electrical motors-A review", IEEE Trans. On Ener. Conv., Vol. 20(4), pp. 719-729, 2005

[8] S. Liu, S. Clénet, T. Coorevits, J.C. Mipo, "Influence of the stator deformation on the behaviour of a claw pole generator", 17th International Conference on Electrical Machines and Systems (ICEMS), Oct. 22-25, Hangzhou, China, pp. 358-362, 2014.

[9] S. Clénet, "Uncertainty quantification in computational electromagnetics: the stochastic approach", ICS Newsletter, March 2013

[10] S. Liu, T. Coorevits, S. Clénet, J.C. Mipo, "Stochastic model of rotating machine eccentricity based on dimensional metrology", IEEE Transaction on Industrial Electronics, submitted.

[11] P. Offermann, H. Mac, T.T. Nguyen, S. Clénet, H. De Gersem, K. Hameyer, "Uncertainty quantification and sensitivity analysis in electrical machines with stochastically varying machine parameters", Vol. 51(3), 2015

[12] T.T. Nguyen, D.H. Mac, S. Clénet, " Non instrusive uncertainty quantification method for models with a high number of parameters Application to a magnetoelectric sensor", Compumag 2015, Montreal, Canada

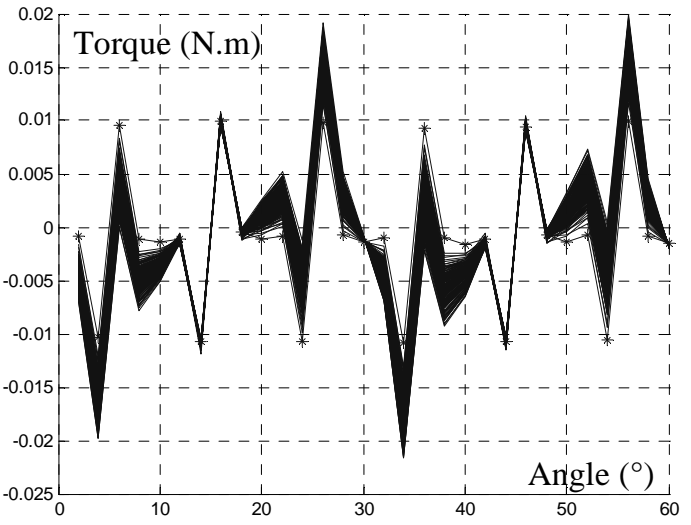

Fig. 6. Superposition of the 200 torque wave shapes (solid lines) compared to the torque of the ideal machine (line with + )

TABLE II

SOBOL INDICES (\%) CALCULATED FOR THE HARMONIC 12 WHEN CONSIDERING THE STATOR DEFORMATION

\begin{tabular}{lllllll}
\hline \hline $\mathrm{I}(\mathrm{A})$ & $\mathrm{h} 0$ & $\mathrm{~h}_{\sin 2}$ & $\mathrm{~h}_{\cos 2}$ & $\mathrm{~h}_{\sin 3}$ & $\mathrm{~h}_{\cos 3}$ & $\mathrm{~h}_{\sin 6}$ \\
\hline 0.5 & 1.75 & 0.07 & 0.08 & 0.03 & 0.02 & 97 \\
4 & 0 & 0.02 & 0.06 & 0 & 0 & 97 \\
\hline
\end{tabular}

